\title{
Preparing a Questionnaire for a Business Report
}

Roz Bukowski

In my business writing classes, I usually use imaginary situations for the writing assignments. When a real-life situation arose, I was glad to challenge my students with preparing a questionnaire to be used by the ESL program. Furthermore, the students used this questionnaire as an important part of their report assignment. The steps simulated the procedure followed in many business situations and hence helped students develop knowledge of business procedures and related language skills. The students worked through all the steps, experienced problems, solved the problems, and wrote a real business report in their writing course.

Having taught business writing for several semesters, I was pleased to have the opportunity to involve my students in a real-life business writing experience. The 16 students in my advanced ESL writing class met the challenge with which I presented them. As in any business situation, the students experienced the process of starting a project, being interrupted, doing research, writing, analyzing, and revising. Throughout the four-week activity, they had instruction and assignments in all aspects of report writing while awaiting the compilation of the questionnaire results needed for the actual report.

Furthermore, this experience demonstrates that "providing real or quasireal life experiences allows more opportunities for language learners to receive input. Interacting and cooperating with others allows opportunities for feedback on one's own language learning and humanizes the learning process" (Eyring, 1991, p. 347). They developed close relationships with their classmates, saw the need for cooperation and careful planning of time, and realized the importance of precise writing.

At the request of the head of my ESL program, I "walked" my advanced English for Business Purposes (EBP) writing class through a situation patterned after one that exists in business in order to prepare them for report writing and to give the head some essential information needed for improving the services to our students.

I began by giving the students an overview of a business report. They then wrote sample report introductions based on several scenarios, which they discussed in groups to determine appropriate information to be in- 
cluded. Following this, I presented a problem: "Our ESL program lacks classroom space and living accommodations. What should we do?"

Based on group and class discussions, the consensus was that ESL needed its own building on campus. Through guided discussions, we determined that to persuade the university, city, and province to provide funding for such a building, we had to show them how much the students contribute to the economy of the city. We concluded that some research was necessary. We searched and found a previous survey of students' reasons for choosing this university and their living expenses here. This was a limited study that needed to be expanded, updated, and formalized.

We decided that a new questionnaire should be prepared to elicit more information from our students. As a class, we determined the information to be solicited. We then invited the Sample Survey and Data Bank Unit (SSDBU) to assist us in preparing the questionnaire (see Appendix A) and in compiling the results. Two members from this unit came to the class to provide guidance in preparing and conducting this survey. These two members worked with us throughout the entire process (they were in the class four times during the four-week activity) providing invaluable assistance and displaying great respect for the students' suggestions and concerns. Among the activities were:

1. Evaluating the students' survey questions.

2. Explaining the rationale for arranging the questions in a particular order.

3. Suggesting changes.

4. Providing guidelines.

5. Field-testing.

6. Revising, revising, revising.

This relationship certainly simulated the relationship that occurs in a real business situation when research is necessary and outside assistance is required. Another benefit was that the students had the opportunity to communicate with people outside the ESL program.

Before the questionnaire was field-tested, we sent it to the graduate studies' ethics committee for approval. It was this committee that suggested that these questionnaires be sealed and delivered directly to Sample Survey for processing to prevent any feelings of intimidation if some ESL students did not wish to participate. This procedure was one with which the students were not familiar, though it was required by our university. This proved to be a useful cultural learning experience.

SSDBU worked with us as we pretested the questionnaire, clarified, deleted, rearranged, and made additions. We prepared an instruction sheet for all the students who would administer the questionnaire, informed all the instructors of the classes involved, prepared a timetable for the students who would visit the classes, and undertook a role-playing exercise to practice the survey procedure. The students delivered their sealed envelopes to SSDBU 
for processing. The results were received on March 11, 1997. This entire experience was invaluable to the students because it was both realistic and relevant.

The development and processing of the questionnaire, however, was only the beginning of the exercise. Working in pairs or small groups, the students then had to write a complete proposal for an ESL building on campus. They could now use the results of the survey to support their proposal, but also had to write a letter of transmittal (covering letter), summary, introduction, body, and conclusion/recommendation.

While I was waiting for the compilation of the results, I continued giving instruction in writing the other parts of the report, in the use of parallelism for the report headings, in the use of numbers, in conciseness, and in the appropriate business writing style.

For each proposal, the students involved had to decide which results would support their particular focus. Would the emphasis be on expenditures, reasons for choosing this particular program, or housing? The focus varied, and consequently specific data had to be chosen to support logically whatever particular focus was selected. For example, if the focus was to be on expenditures, those data would be taken from the survey and would be highlighted to support the argument.

The benefits of this project to the students included the following.

1. This hands-on approach allowed the students to use their previously learned skills. One student, for example, already had his degree in business administration and had done similar work in his country. Others had also been in the work force and were familiar with some aspects of the process.

2. This exercise was realistic in the English-for-business context.

3. The skills learned could be transferred from the classroom to the students' future careers.

4. This project improved their listening/speaking skills and their business writing skills. With the presence of two new "instructors" in the class, they had the opportunity to listen to new voices. When conducting the survey, they practiced their speaking skills in every ESL session in the program. They had countless writing exercises to practice writing all the parts of the report. The organization of a report was also stressed, so they learned the appropriate report format.

5. This project demonstrated the importance of clear and precise writing. Many changes were made to survey questions initially believed to be adequate and suitable.

6. This project stressed the importance of teamwork. The students engaged in many group discussions to talk over their purpose, the relevant information to include, and the report organization. 
7. The students appreciated the value of this exercise. Some comments were:

- Although this assignment was difficult, it showed me what to expect when I leave university.

- Now I will know how to organize a report.

- Canadians have very strict guidelines in what they can and cannot do, but I, at least, understand the protocol.

- It's easier to write a report when there is a definite organization to follow.

- It's helpful to know the kind of information that should be included in the different parts of a report.

- The Canadian business writing is very direct-so much so that it even seems rude. I would not be so direct in my own country.

- I wish I would have decided to write the report by myself rather than with a partner. I found this interesting because we had had a lively discussion in class about the advantages and disadvantages of writing alone vs. writing with a partner(s).

As the instructor, I also enjoyed some benefits:

1. I learned the rationale behind a questionnaire's organization.

2. I gained a new respect for the expertise of my students.

3. I enjoyed observing the mutual respect displayed between the SSDBU experts and my students.

4. This project provided valuable information to be used for recruiting and improving services to ESL students.

\section{The Author}

Roz Bukowski (BA, Professional A Teaching Certificate, TESL Certificate) has been an instructor at the University of Regina for 15 years, teaching courses and working on curriculum. Roz has also taught writing courses and given writing workshops on a contract basis for government and business agencies for the past 20 years.

\section{Reference}

Eyring, J.L. (1991). Experiential language learning. In M. Celce-Murcia (Ed.), Teaching English as a second or foreign language (2nd ed., pp. 346-355). Boston, MA: Heinle \& Heinle.

\section{Appendix A \\ ESL Survey, 1997}

\section{WE'RE ASKING FOR YOUR HELP ...}

The purposes of this survey are to:

- Gather information from ESL students about their program and experiences.

- Use the information to maintain and improve the services provided to ESL students. 


\section{WHAT YOU'RE ASKED TO DO ...}

To take about 10 minutes to complete the attached questionnaire. When you're finished, put it in the envelope, seal it, and hand it in to one of the ESL 051 students attending your class today. They will be sending the envelopes directly to Sample Survey without opening them.

Whether or not you complete this survey will not affect your grade or standing in the ESL program. We are asking for your help in gathering information needed to maintain and improve the ESL program.

\section{MUST YOU FILL IT OUT ...}

NO: Whether you complete the survey is entirely up to you: participation is voluntary. You do not have to fill out the questionnaire if you do not want to. If you do not, just put the questionnaire into the envelope and seal it.

AS WELL! You do not have to answer every question. If you do not want to answer a question, go on to the next one.

HOWEVER: We want to make sure the results of our survey represent your experiences and the experiences of other students like you in ESL, so we ask that you seriously consider giving us ten minutes of your time to complete the questionnaire. The results will be important for providing services to ESL students in the future.

\section{WILL ANYONE KNOW YOUR ANSWERS ...}

NO. The information will be kept strictly confidential and anonymous. Please do not write your name on the questionnaire or the envelope. The questionnaires will be processed by Sample Survey. ESL will get only a summary of the results. No student can be identified from the summary.

\section{CAN YOU GET RESULTS ...}

If you would like a summary of the results of the survey, contact Roz Bukowski, ESL, Languages Institute.

\section{READY TO START ...}

Please follow the instructions for each question. Ask for help if you have questions. SECTION A: First, some questions about the ESL program and the University of Regina.

A1. What ESL class are you now taking? (Please check one.)

$\begin{array}{rrr}020 & 030 & 032 \\ 0 & 031 & 030\end{array}$

A2. How did you find out about the University of Regina ESL program? (Please check one.)

From friends/relatives at home From friends/relatives in Canada From a placement agent From my own research of Universities
From another Canadian university From a government or public agency Other:

A3. When you were thinking about coming to the University of Regina for ESL, how important were the following reasons in making your decision? Tell us how important each one was on a scale of 1 (very important) to 4 (not at all important). 
Reasons for choosing $\mathrm{U}$ of $\mathrm{R}$ :

1. Lower cost of tuition than other Universities

2. Low number of students from the same country

3. Good standard of English/good program

4. Low cost of living in Regina

5. Good place to study--no distractions

6. Agent's recommendation

7. A safe place

8. A clean environment

9. Easy to get into University of Regina

10. Other:
Very Somewhat Not Very Not at All Important Important Important Important

$\begin{array}{llll}1 & 2 & 3 & 4 \\ 1 & 2 & 3 & 4 \\ 1 & 2 & 3 & 4 \\ 1 & 2 & 3 & 4 \\ 1 & 2 & 3 & 4 \\ 1 & 2 & 3 & 4 \\ 1 & 2 & 3 & 4 \\ 1 & 2 & 3 & 4 \\ 1 & 2 & 3 & 4 \\ 1 & 2 & 3 & 4\end{array}$

A4. What was your single most important reason for deciding to come to Regina for ESL? Please write the number for that one reason (from question A3) in this space:

A5. What is your main reason or goal for taking ESL? (Please check one.) To learn English so I can enter university. To learn English for my work or business To learn English for my own interest To learn about North American culture Other (please specify)

SECTION B: Next, some questions about your experiences here in Regina.

B1. What kind of housing do you stay in now-where do you live? (Please check one.)

Homestay

University residence

Apartment or house by myself
___ Apartment or house with others With relatives Other:

B2. What kind of housing would you prefer to stay in-where would you prefer to live? (Check one.)

Homestay

University residence

Apartment or house by myself

___ Apartment or house with others With relatives

Other:

B3. For this semester, how much will you spend on university tuition, books, and supplies?

\section{$\$$}

B4. Did you or will you make major one-time purchases? Please check which one-time purchases you made or will make and enter how much will be spent in each category.

Did or will you purchase:

(1) Yes

(2) No

Cost? (\$)

1.Car/licence/insurance

2. Furniture

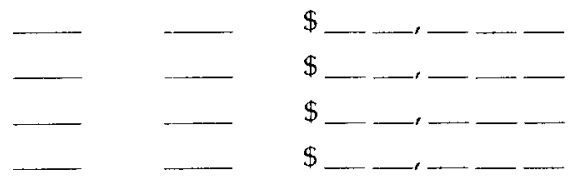

3. Computer

4. TV/Stereo/VCR 
5. Medical insurance

6. Dental care

7. Eyeglasses

8. Airfare bought in Regina

9. Recreation equipment

10. Other:

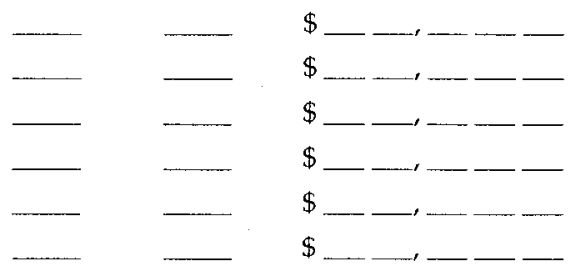

B5. On average how much will you spend per month on the following? Please circle the number in each category that indicates how much you will spend.

spent per month on:

Less than $\$ 200$ to $\$ 500$ to more than $\$ 200 \quad \$ 500 \quad \$ 1,000 \quad \$ 1,000$

1. Housing:

1

2

3

4

(including rent of house/apartment/

room; homestay; rental of furniture/

appliances; insurance; utilities; etc.)

2. Transportation:

(including bus; taxi; car rental/repairs/

1

2

3

4

insurance/gasoline/parking/;etc.)

3. Food:

(including meals; snacks; groceries; etc.)

4. Clothing:

5. Personal:

(including toiletries; prescriptions,

drycleaning; hair care; etc.)

6. Entertainment and Recreation:

(including movies; concerts; sports events;

rent of TV/VCR/stereo/cable;

magazines/newspapers;

7. Miscellaneous:

(other including membership fees; bank

charges, etc.)

SECTION C: Now, a few questions about your background.

$\mathrm{C} 1$. What age group are you in?

(1) _... 18 or younger (2) __ 19 to $21 \mathrm{yrs}$.

C2. Are you

(1) Male or

(2)

(3)

22 to $25 \mathrm{yrs}$.

(4)

3

4

12

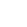

4

$\begin{array}{llll}1 & 2 & 3 & 4 \\ 1 & 2 & 3 & 4\end{array}$

1

2

3

4

C3. What country do you come from? (Please check one.)

\begin{tabular}{ll} 
China & Vietnam \\
Hong Kong & Mexico \\
Japan & Colombia \\
Korea & Brazil \\
Taiwan & Other: \\
\hline Thailand &
\end{tabular}

THANK YOU VERY MUCH FOR COMPLETING THIS QUESTIONNAIRE! 